\title{
NICKEL NANOPARTICLES MODIFIED CARBON PASTE ELECTRODE FOR NI IONS DETERMINATION AND ITS THERMODYNAMICS STUDY
}

\author{
Sayyed Ahmad Nabavi - Amri ${ }^{1}$, Tahereh Sadeghi ${ }^{2}$, Mohammad Mahdi Norouzi ${ }^{3}$ \\ ${ }^{1,3}$ School of Chemistry, Damghan University, Damghan, Iran, \\ ${ }^{2}$ Education office, Feridonkenar, Iran \\ nabavi@du.ac.ir,156_sadeghi@yahoo.com,m.norouzi@std.du.ac.ir
}

\begin{abstract}
Novel potentiometric electrodes were assembled with the carbon paste by nickel nanoparticles. Nickel nanoparticles were produced in acidic reducing solutions. Resulted product characterized by scanning electron microscopy (SEM) and X-ray diffraction (XRD). The properties of the modified electrodes at different concentrations were studied by electrochemical impedance spectroscopy (EIS) and potentiometry. Our results showed that Nickel nanoparticles increase the electrode/solution interface capacitance, constant phase element $(C P E)$ and also increase the interface resistance. These electrodes that showed good sensitivity, reproducibility and stability can potentiometricaly determine Nickel ions. We studied thermodynamic parameters of fabricated electrodes.
\end{abstract}

Keywords: Nickel nanoparticle, Carbon paste electrode, EIS, XRD, Electrode thermodynamics. $* * *$

\section{INTRODUCTION}

In recent years, increasing interest has been focused on the synthesizing nanoscale particles and clusters [1-5]. The physical and chemical properties vary drastically with size and the use of ultra-fine particles represents a potentially fertile field for materials research[6,7]. Ni nanoparticles are one of the interesting materials for advanced technology [7]. In this investigation, we described a process for preparing $\mathrm{Ni}$ nanoparticles by reducing metal salt from aqueous solution with reducing agent and use of this product to construction of a modified potentiometric carbon paste electrode. Scanning electron microscopy (SEM) showed the cluster shape of Ni. We determined grain size by XRD spectrum of nanoparticles using scherrer equation. The factors affecting the electrode usage due to nanoparticle properties were studied in order to establish the optimum operating conditions and to explore practical applications of the technique. At the first step, five different nanoparticles ratios than the other electrode's components (graphite powder and nujol oil) were examined. At the next, with this accepted ratio, we study the electrode response to 21 of $\mathrm{Ni}^{2+}$ concentration points. In addition, the electrodes were characterized by thermodynamics study at temperature range from 298 to $338 \mathrm{~K}$ by 5 degrees steps. Electrochemical impedance spectroscopy (EIS) studies were conducted with 6 different concentrations of $\mathrm{Ni}$ ions. EIS studies showed good agreements to potentiometric applications.

\section{EXPERIMENTAL METHODS}

\subsection{Materials}

Materials used in this work were nickel acetate, $\mathrm{Ni}\left(\mathrm{CH}_{3} \mathrm{COO}\right)_{2} \cdot 4 \mathrm{H}_{2} \mathrm{O}$, acetic acid, sodium hypophosphite, $\mathrm{NaH}_{2} \mathrm{PO}_{2} \cdot \mathrm{H}_{2} \mathrm{O}$, graphite powder and nujol oil that all of these materials were reagent grade.

\subsection{Electrochemical Measurements}

A saturated calomel electrode (SCE) was used as reference. Potentiometric measurements were carried out with a Metrohm 645 Potentiometer. A Pentium $4 \mathrm{CPU} 1.7 \mathrm{GHz}$ computer processed data. Electrochemical impedance spectroscopy (EIS) were carried out with an AUTOLAB/PGSTAT30 system equipped to frequency response analysis (FRA2) program at range of $10 \mathrm{mHz}$ to 100 $\mathrm{kHz}$ with $5 \mathrm{mV}$ perturbation signal at equilibrium potential. Each of measurements repeated 10 times.

\subsection{Micrographic Analysis}

The surface and morphology of the nickel nanoparticles was characterized by model Stereo Scan 360 of scanning electron microscope (SEM).

\subsection{X-Ray Diffraction Study}

XRD spectrum of Ni nanoparticles that used to determination of particle's size and crystallinity were carried out by Btuker axs D8 of X-ray diffractometer. 


\subsection{Preparation of Ni nanoparticles}

Preparation of $\mathrm{Ni}$ nanoparticles is highly sensitive to conditions[8-10]. Solutions containing nickel ions were prepared by dissolving analytical grade nickel acetate, $\mathrm{Ni}\left(\mathrm{CH}_{3} \mathrm{COO}\right)_{2} .4 \mathrm{H}_{2} \mathrm{O}$, in distilled water. The $\mathrm{pH}$ values of the solutions were adjusted by addition of acetic acid. We were used no surfactants. Sodium hypophosphite solutions, $\mathrm{NaH}_{2} \mathrm{PO}_{2} \cdot \mathrm{H}_{2} \mathrm{O}$, were used as the reducing agent. The mixture was heated to $85 \pm 1{ }^{\circ} \mathrm{C}$. Conditions of $\mathrm{Ni}$ ions reducing bath are listed in table 1 . The black powder was separated from the solution by centrifugal separation, and washed with distilled water followed by ethanol and acetone. The powder was finally dried in a vacuum oven at $40^{\circ} \mathrm{C}$ for 24 hours. Figure 1 shows SEM micrograph of powder. This figure used in morphological studies of nanoparticles that seems to be cluster. We determined grain size using scherrer equation [11$13]$ by XRD spectrum of nanoparticles that shown in figure 2 . This method gives $3.14 \mathrm{~nm}$ of grain size.

Table-1: Conditions of Ni nanoparticles producing bath.

\begin{tabular}{|c|c|}
\hline subject & description \\
\hline $\mathrm{Ni}\left(\mathrm{CH}_{3} \mathrm{COO}\right)_{2} \cdot 4 \mathrm{H}_{2} \mathrm{O}$ & $16.9 \mathrm{gr} / \mathrm{lit}$ \\
\hline $\mathrm{NaH}_{2} \mathrm{PO}_{2} \cdot \mathrm{H}_{2} \mathrm{O}$ & $25.4 \mathrm{gr} / \mathrm{lit}$ \\
\hline Acetic acid & Adjustment of $\mathrm{pH}$ value \\
\hline $\mathrm{pH}$ & 4 \\
\hline Temperature & $85 \pm 1{ }^{\circ} \mathrm{C}$ \\
\hline
\end{tabular}

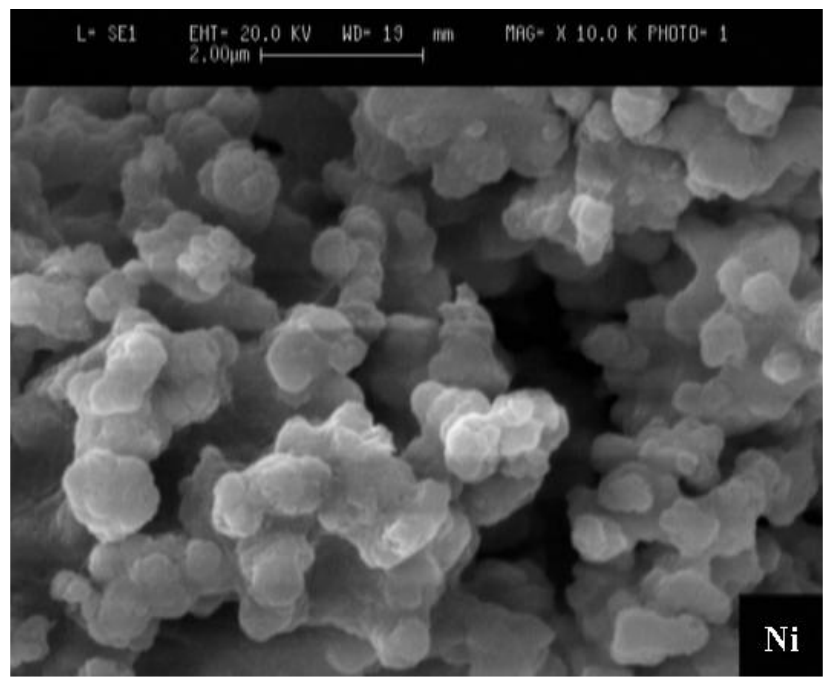

Fig -1: photo of Ni nanoparticles that shows the particles grow to clusters.

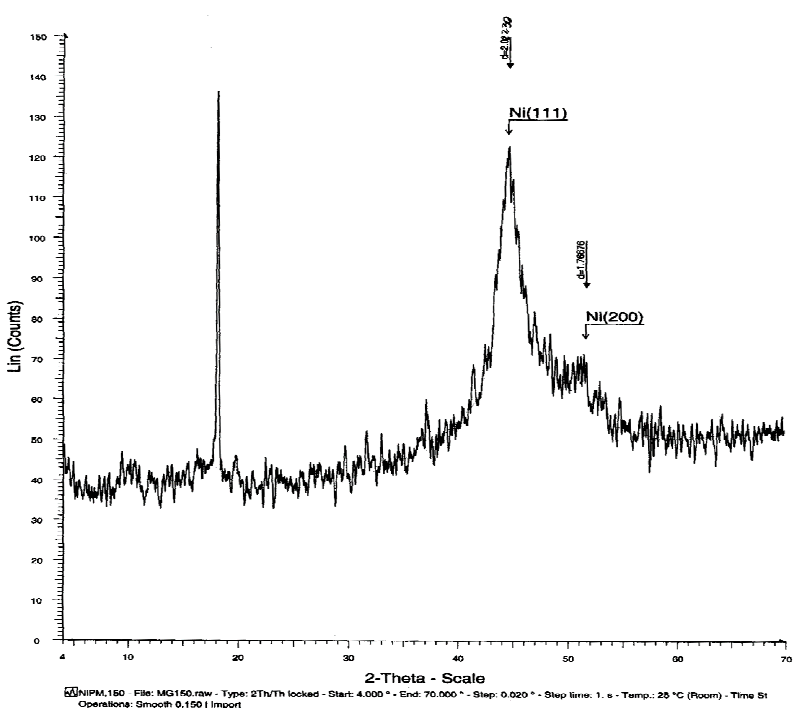

Fig -2: XRD spectrum of Ni nanoparticles that used to determination of particle's size and crystallinity. (Note that the sharp peak at $2 \theta=18$ is due to PTFE sample holder).

\subsection{Construction of Modified Carbon Paste Electrode}

A 6 7 cm long polyethylene tube (a piece of Insulin injection syringe) used as electrode wall. About $0.1 \mathrm{gr}$ of the paste prepared by exactly weighted $\mathrm{Ni}$ nanoparticles, graphite powder and nujol oil put into one end of the tube. From the other side of the tube, a copper wire inserted into the paste, as shown in figure 3 . This wire, make electrically connection between the paste and the potentiometer instrument.

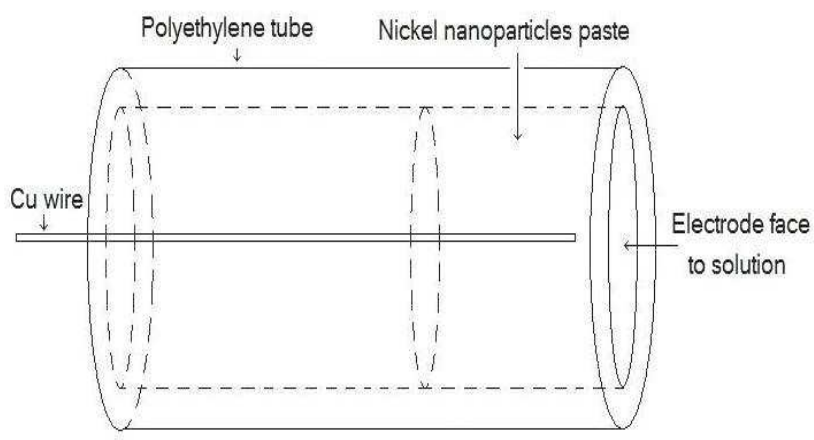

Fig- 3: Compartments of electrode assembly

\section{RESULTS AND DISCUSSION}

\subsection{Optimization of Electrode Components}

In our electrodes, $\mathrm{Ni}$ nanoparticles are the active spices and therefore the ratio of $\mathrm{Ni}$ to the other contaminating spices must be adjusted. We examine five ratios, shown in figure 4; of $\mathrm{Ni}$ 
to graphite powder (in figure 4 abbreviated to $\mathrm{C}$ ). We found that $36 \%$ of paste must be nujol oil to maintain its paste form. According to flatten, wide spread and low slope; $\mathrm{Ni}$ /graphite/nujol oil ratio same to 20/44/36 accepted for continued studies.

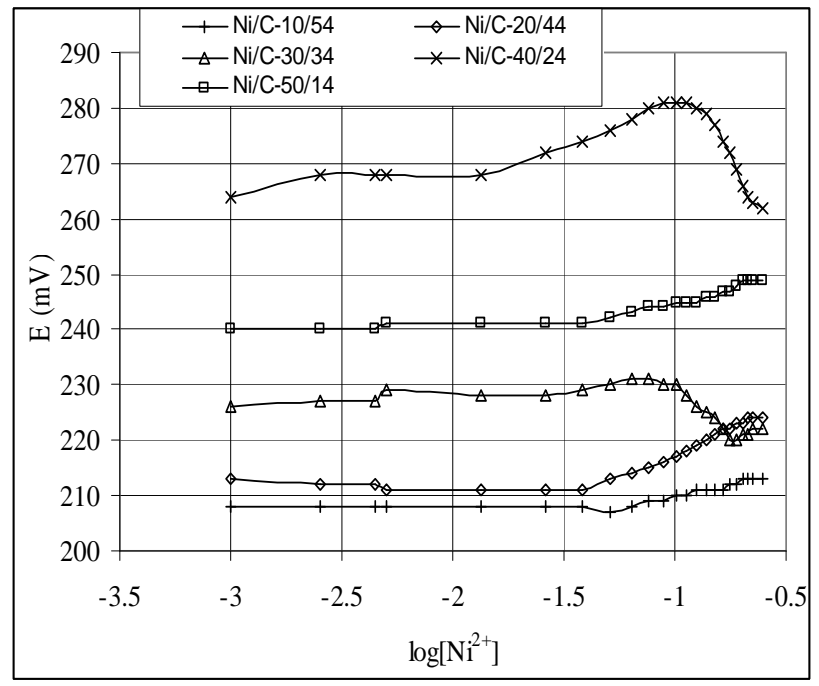

Fig- 4: Variation of electrode potential vs. $\log \left[\mathrm{Ni}^{2+}\right]$ for different $\mathrm{Ni} / \mathrm{C}$ ratio (C synonyms to graphite). In all curves nujol oil fixed to $36 \%$.

\section{3-2 Electrode Response to $\left[\mathrm{Ni}^{2+}\right]$ And Temperature}

We measured electrode potentials vs. SCE for $\left[\mathrm{Ni}^{2+}\right]$ from 0.0115 to $0.1113 \mathrm{~mol} / \mathrm{lit}$ by 21 steps proposed to cover the linear range of electrode. The measurement applied to temperatures from 298 to $338 \mathrm{~K}$ by 4 steps. Results reported in Table 2. Each of points measured 5 times, and reported results are the confident averages. These results are the basis for thermodynamics study on modified electrode and also to estimate its performance to determination of $\left[\mathrm{Ni}^{2+}\right]$. Figure 5 shows variations of electrode potentials vs. $\log \left[\mathrm{Ni}^{2+}\right]$.

Table 2. Electrode potentials for $\left[\mathrm{Ni}^{2+}\right]=0.0115$ to 0.1113 $\mathrm{mol} / \mathrm{lit}$ at different temperatures from 298 to $338 \mathrm{~K}$.

\begin{tabular}{|c|c|c|c|c|c|}
\hline \multicolumn{6}{|c|}{ Potential $(\mathrm{mV})$} \\
\hline$\left[\mathrm{Ni}^{2+}\right]$ & $\mathrm{T}=298 \mathrm{~K}$ & $\mathrm{~T}=308 \mathrm{~K}$ & $\mathrm{~T}=318 \mathrm{~K}$ & $\mathrm{~T}=328 \mathrm{~K}$ & $\mathrm{~T}=338 \mathrm{~K}$ \\
0.0115 & 206 & 192 & 162 & 144 & 119 \\
0.0165 & 208 & 196 & 166 & 146 & 122 \\
0.0214 & 210 & 201 & 169 & 148 & 128 \\
0.0264 & 211 & 200 & 172 & 151 & 132 \\
0.0314 & 213 & 202 & 174 & 153 & 135 \\
0.0364 & 214 & 204 & 177 & 156 & 139 \\
0.0414 & 215 & 207 & 178 & 158 & 142 \\
0.0464 & 216 & 208 & 180 & 160 & 145 \\
0.0514 & 217 & 209 & 182 & 162 & 148
\end{tabular}

\begin{tabular}{l|l|l|l|l|l|}
0.0564 & 217 & 210 & 184 & 164 & 150 \\
0.0614 & 218 & 212 & 185 & 167 & 152 \\
0.0664 & 218 & 212 & 186 & 169 & 153 \\
0.0714 & 219 & 215 & 187 & 171 & 155 \\
0.0763 & 220 & 215 & 189 & 173 & 157 \\
0.0813 & 223 & 215 & 190 & 176 & 158 \\
0.0863 & 223 & 216 & 191 & 177 & 159 \\
0.0913 & 224 & 217 & 192 & 178 & 160 \\
0.0963 & 226 & 217 & 193 & 179 & 161 \\
0.1013 & 226 & 218 & 193 & 180 & 162 \\
0.1063 & 227 & 218 & 194 & 180 & 162 \\
0.1113 & 227 & 218 & 195 & 180 & 163 \\
\hline
\end{tabular}

Plot of electrode potentials vs. $\log \left[\mathrm{Ni}^{2+}\right]$ for each temperatures, (shown in figure 5), indicate that: a) it has different slopes that means it has different values of $\mathrm{n}$ (transferred electron number); b) however, slope of curves for each of temperatures, shows that electrode has low deviation and behaves quasi-Nernstian[14]; c) good values of correlation coefficient for each temperatures make the curves acceptable, therefore we can study this electrode in the range of $\log \left[\mathrm{Ni}^{2+}\right]=$ -0.9 to -1.9 .

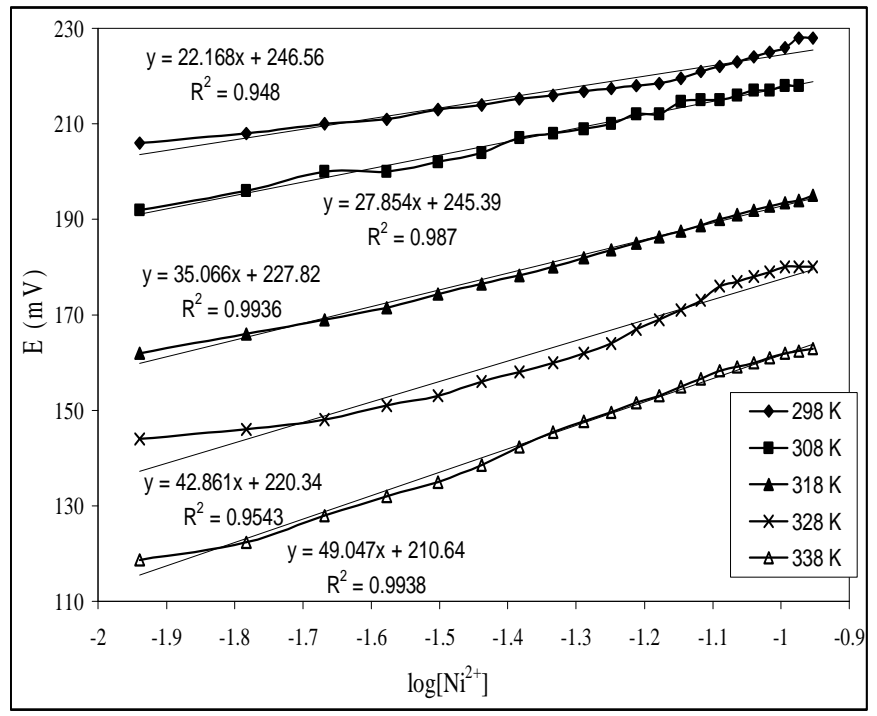

Fig- 5: Electrode potentials vs. $\log \left[\mathrm{Ni}^{2+}\right]$ at different temperatures from 298 to $338 \mathrm{~K}$ and the fitted curves.

Figure 6 shows experimental transferred electron number $\left(\mathrm{n}_{\text {exp }}\right)$ at various temperatures. Values for this figure obtained from slope of curves in figure 5; Slope $=(2.303) \mathrm{RT} / \mathrm{nF}$. This values to be used in calculation of thermodynamic quantities $(\Delta \mathrm{G}, \Delta \mathrm{H}$ and $\Delta \mathrm{S})$. 


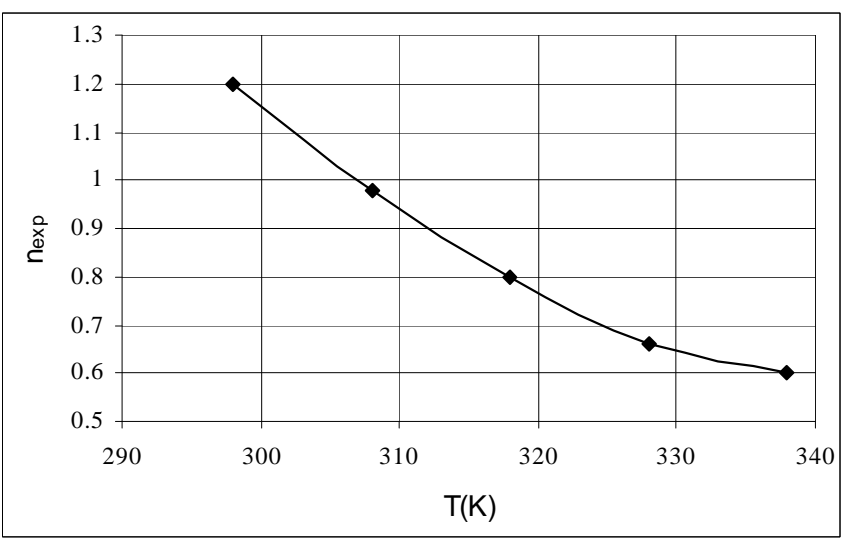

Fig- 6: Experimental transferred electron number at various temperatures.

Among the more number of $\left[\mathrm{Ni}^{2+}\right]$ that we have studied, the compositions symbolized in figure 7 , have been shown in figures 8 to 10 . Also, for more clearance in each figures, we sketch average of studied object vs. $\left[\mathrm{Ni}^{2+}\right]$ in.

\begin{tabular}{|c|c|c|}
\hline$\longrightarrow 0.0115 \mathrm{~mol} / \mathrm{lit}$ & $\rightarrow-0.0165 \mathrm{~mol} / \mathrm{lit}$ & $\neg-0.0214 \mathrm{~mol} / \mathrm{lit}$ \\
\hline$\rightarrow-0.0264 \mathrm{~mol} / \mathrm{lit}$ & $\multimap 0.0314 \mathrm{~mol} / \mathrm{lit}$ & $\square-0.0364 \mathrm{~mol} / \mathrm{lit}$ \\
\hline$\triangle 0.0414 \mathrm{~mol} / \mathrm{lit}$ & $\cdots \leftrightarrow 0.0464 \mathrm{~mol} / \mathrm{lit}$ & $\cdots-0.0514 \mathrm{~mol} / \mathrm{lit}$ \\
\hline$\cdots-0.0564 \mathrm{~mol} / \mathrm{lit}$ & $\cdots-\cdots \cdots 0.0614 \mathrm{~mol} / \mathrm{lit}$ & $\cdots \leftrightarrow-0.0664 \mathrm{~mol} / \mathrm{lit}$ \\
\hline - - $-0.0714 \mathrm{~mol} / \mathrm{lit}$ & $\cdots-0.0763 \mathrm{~mol} / \mathrm{lit}$ & $-\bullet-0.0813 \mathrm{~mol} / \mathrm{lit}$ \\
\hline$-0.0863 \mathrm{~mol} / \mathrm{lit}$ & $---0.0913 \mathrm{~mol} / \mathrm{lit}$ & $--x--0.0963 \mathrm{~mol} / \mathrm{lit}$ \\
\hline$-\diamond-0.1013 \mathrm{~mol} / \mathrm{lit}$ & - - $0.1063 \mathrm{~mol} / \mathrm{lit}$ & $-\Delta--0.1113 \mathrm{~mol} / \mathrm{lit}$ \\
\hline
\end{tabular}

Fig. 7. Compositions and symbols that have been shown in figures 8 to 12 .

Plot of electrode potentials vs. temperatures for each of $\left[\mathrm{Ni}^{2+}\right]$, (shown in figure 8), indicates that electrode almost behaves identical for all of studied $\left[\mathrm{Ni}^{2+}\right]$. Slope in each regions of any curves is similar to each others. On the other hands, plot behavior of each $\left[\mathrm{Ni}^{2+}\right]$ is uniform to others.

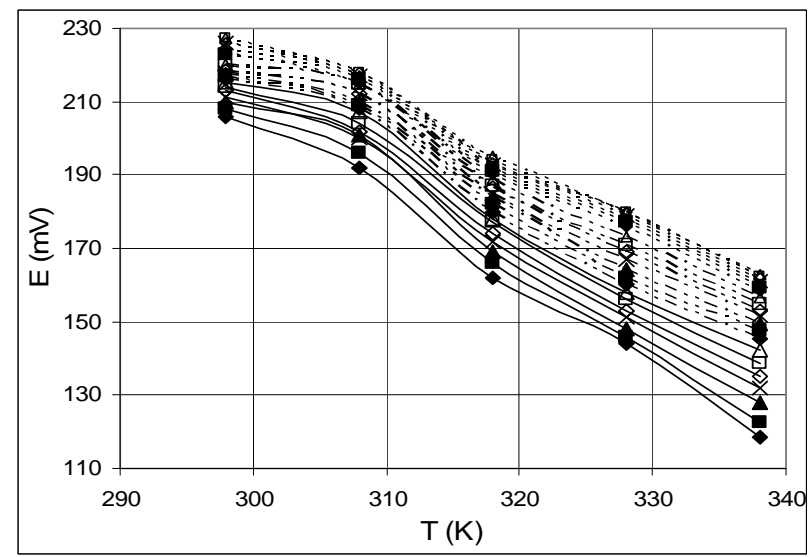

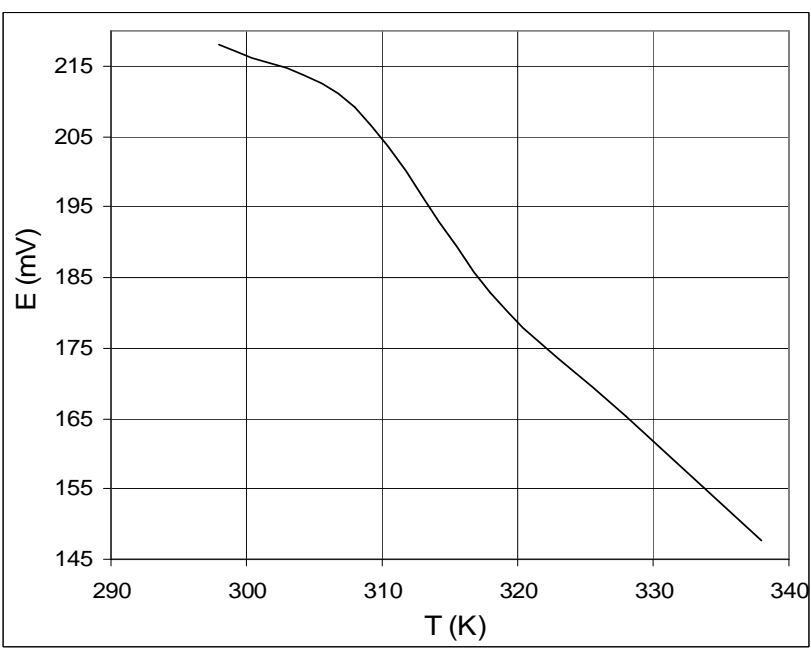

Fig-8: Electrode potentials vs. temperatures: up) for all $\left[\mathrm{Ni}^{2+}\right]$; down) average of all curves of right.

Figure 9 shows electrode temperature coefficient $\left((\Delta \mathrm{E} / \Delta \mathrm{T})_{\mathrm{p}}\right)$ at various temperatures. Low slope values for electrodes is one of the conditions that must accomplish to other conditions such as high impedance and high capacitive effects; to synonymies the electrode as potentiometric element. At higher temperatures electrode reaches equilibrium and has lower value of temperature coefficient. We discuss about this characteristic in continua.

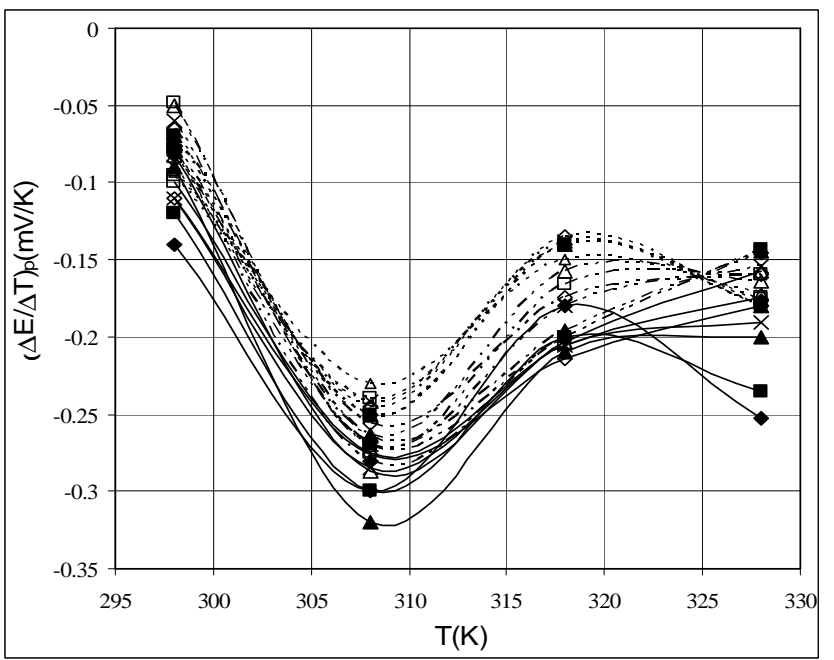

(a) 


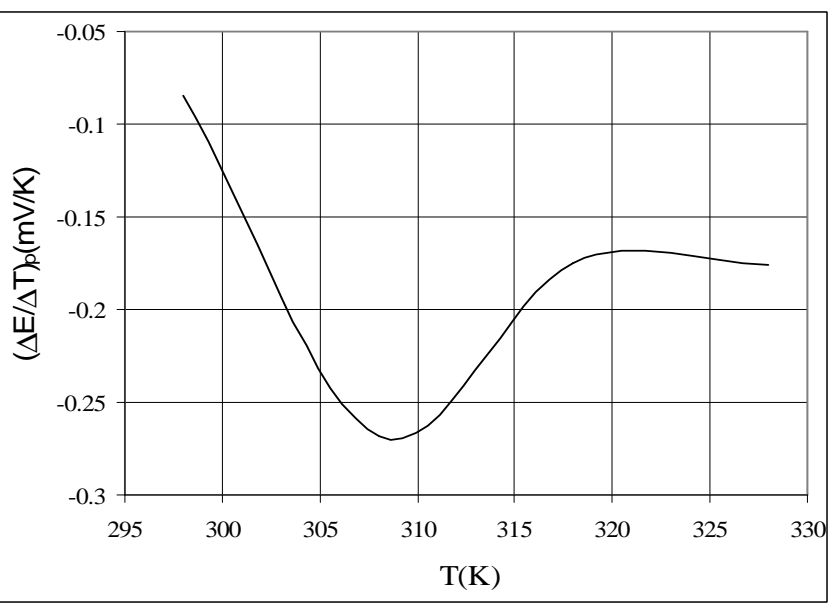

(b)

Fig- 9: Temperature coefficient vs. temperatures: a) for all $\left[\mathrm{Ni}^{2+}\right]$; b) average of all curves of right.

For an electrochemical reaction, at thermal equilibrium, Gibbs free energy could be determined using equation $\Delta \mathrm{G}=-\mathrm{nFE}$. For temperatures' steps, $\Delta \mathrm{T}$, we can determine entropy of reaction, using $\Delta \mathrm{S}=\mathrm{nF}(\Delta \mathrm{E} / \Delta \mathrm{T})_{\mathrm{p}}$ and then enthalpy by $\Delta \mathrm{H}=\Delta \mathrm{G}+\mathrm{T} \Delta \mathrm{S}=-$ $\mathrm{nF}[\mathrm{E}+\mathrm{T}(\Delta \mathrm{E} / \Delta \mathrm{T})$. We calculate Gibbs free energy variation for the electrode reaction using potentials (table 2), experimental electron transfer numbers (figure 5). Thesis values calculated and shown in figure 10. This Figure shows that increase in temperature causes increase in free energy. Slop of these variation decrease at higher temperatures. This means that reaction, $\mathrm{Ni} \rightarrow \mathrm{Ni}^{2+}+2 \mathrm{e}$, goes to run spontaneously at higher temperatures.

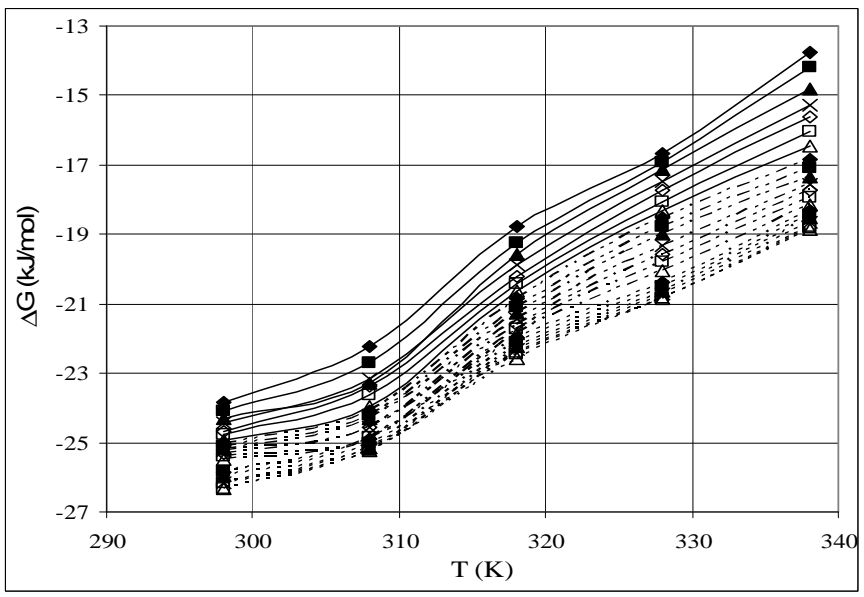

(a)

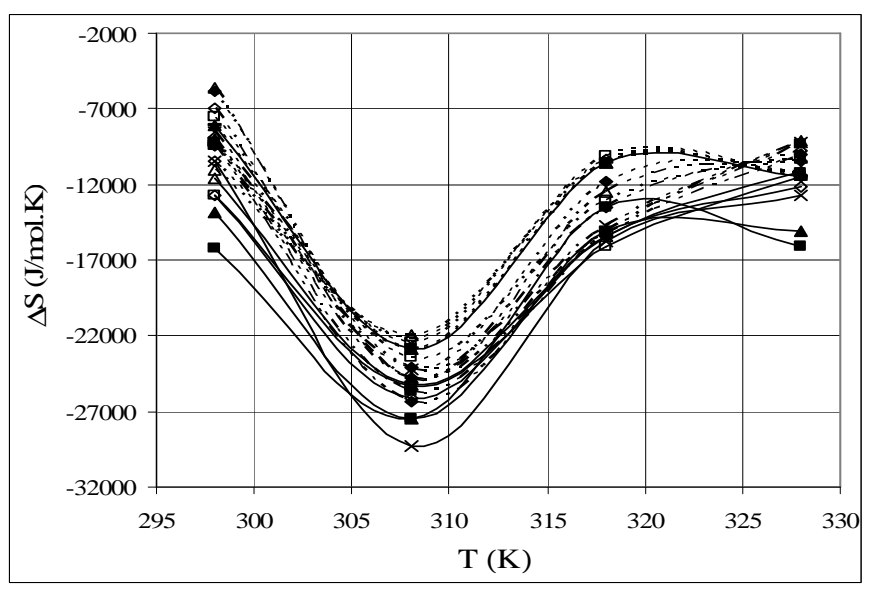

(b)

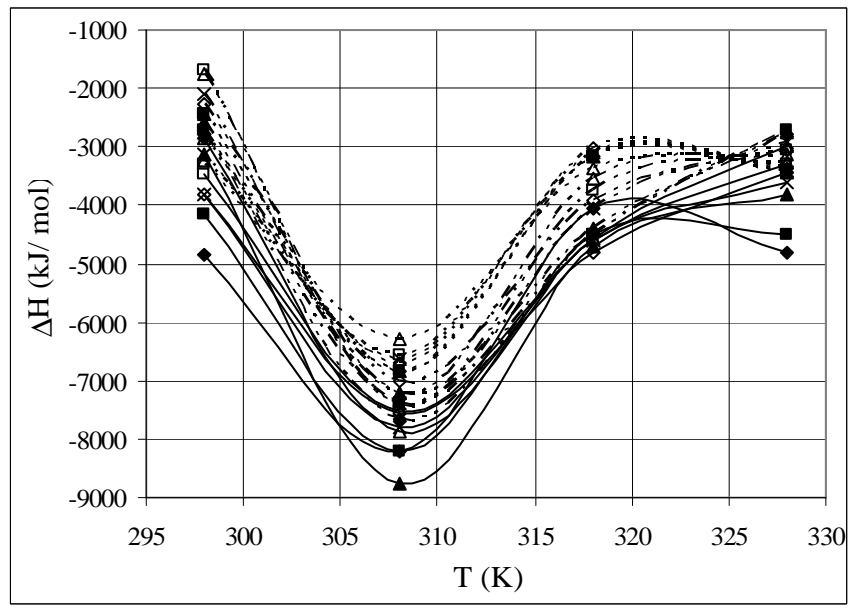

(c)

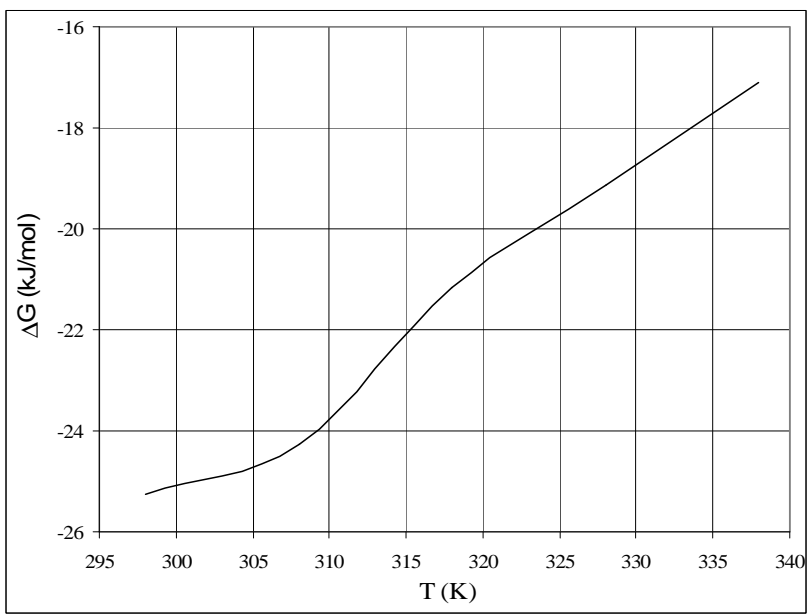

(d) 


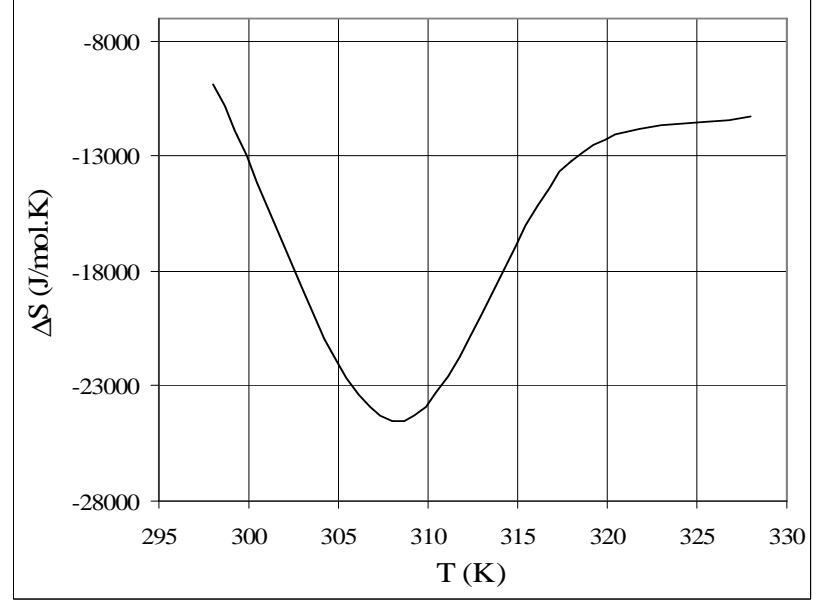

(e)

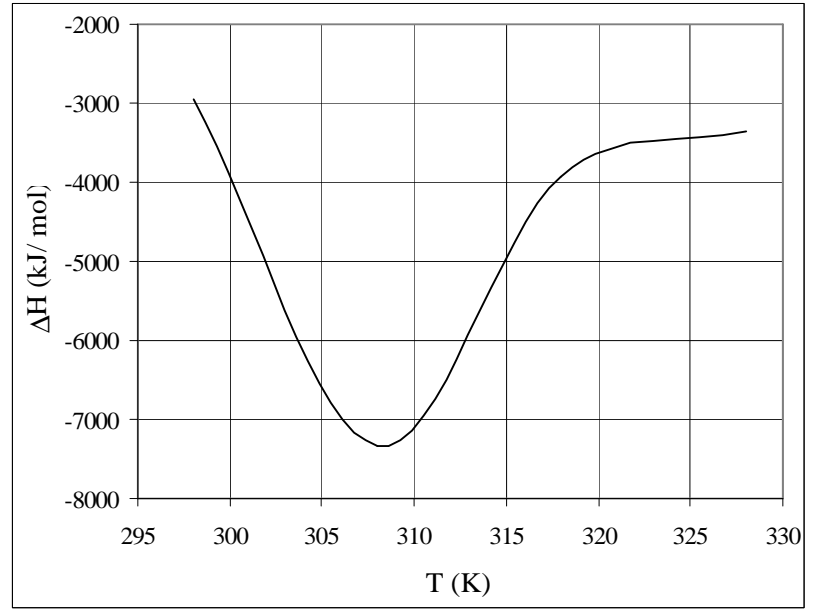

(f)

Fig. 10. Variation of electrode reaction Gibbs free energy, entropy and enthalpy vs. temperatures: $\mathrm{a}, \mathrm{b}, \mathrm{c})$ for all $\left[\mathrm{Ni}^{2+}\right] ; \mathrm{d}$, e, f) average of all curves of $\left[\mathrm{Ni}^{2+}\right]$.

By figure 10, it seems the same rules for variations of enthalpy and entropy. Temperature and concentration, both affects on the system entropy. In aqueous solutions, $\mathrm{Ni}^{2+}$ ions hydrated by some solvent molecules. At a constant $\left[\mathrm{Ni}^{2+}\right]$, by increasing of temperature to $308 \mathrm{~K}$, system is more regular and $\Delta \mathrm{S}<0$ due to higher effect of ions hydration than the thermal motion of them. But at higher temperatures mobility of ions is the influential factor and $\Delta S>0$.

For determination of solution resistance $\left(\mathrm{R}_{\mathrm{s}}\right)$, polarization resistance $\left(\mathrm{R}_{\mathrm{p}}\right)$ and constant phase element $(\mathrm{CPE})$ of electrode; we have done electrochemical impedance study (EIS) on electrode in different $\left[\mathrm{Ni}^{2+}\right]$. Nyquist diagrams shown in figure 11. Interpretation of these diagrams done based on Boukamp principles[15] and using FRA2 program result to calculated values reported in table 3 .
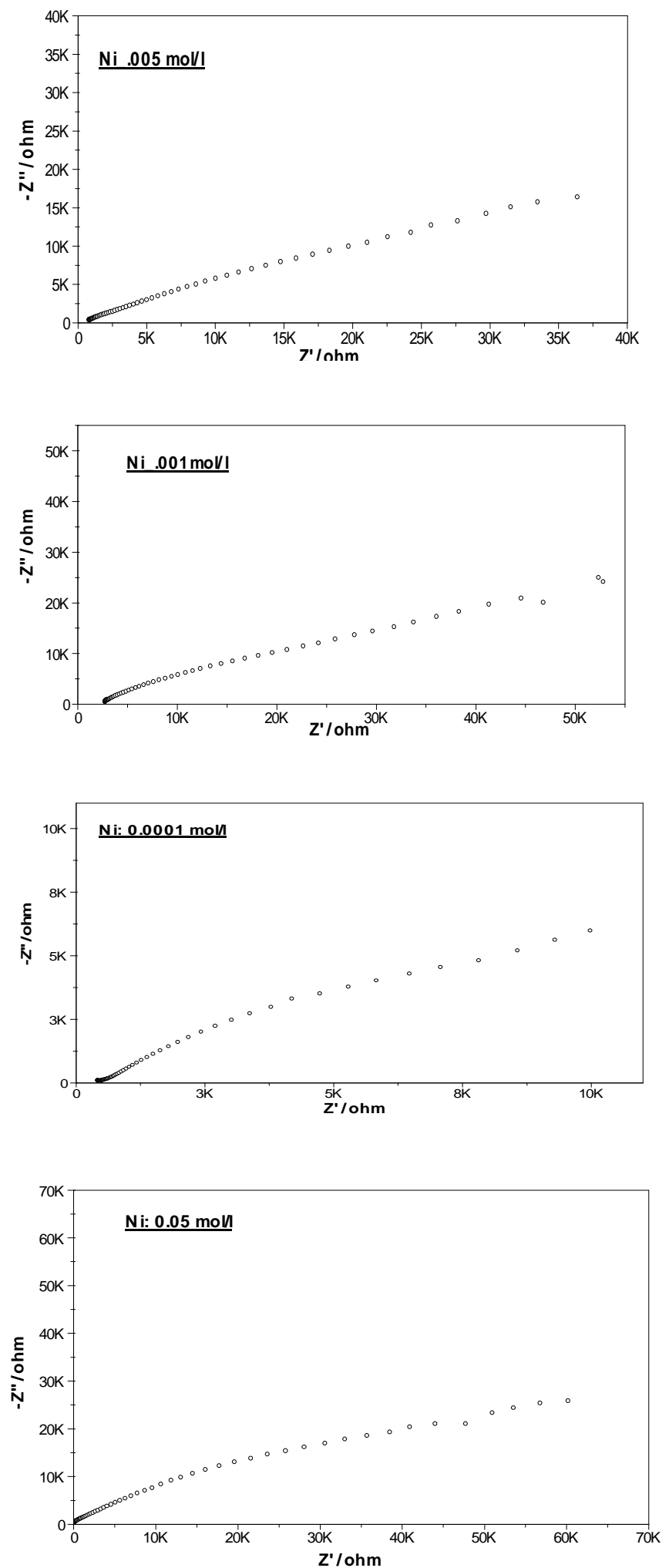


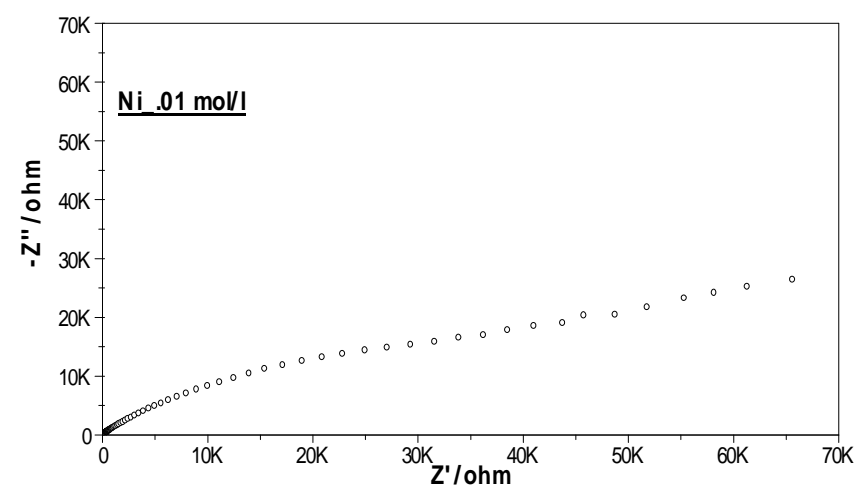

Fig-11: Electrochemical impedance (Nyquist ) diagrams for the studied electrode in different $\left[\mathrm{Ni}^{2+}\right]$

We determined that equivalent circuit for curves of figure 11, is $\left[R_{s}-R_{p} \| C P E\right]$. This means that $R_{s}$ is in series with $R_{p}$ and both are in parallel to CPE. Low values of $R_{s}$, in table 3 , is due to low electrolyte resistance. Semi-circle at high frequency is related to electron transfer process. This semicircle has high diameter that shows the slow rate and also high resistance for electron transfer[15].

Table-3: Values of OCP, resistance and CPE for electrode in various amounts of $\left[\mathrm{Ni}^{2+}\right]$ calculated from Fig. 11.

\begin{tabular}{||c|c|c|c|c|c||}
\hline $\begin{array}{c}{\left[\mathrm{Ni}^{2+}\right]} \\
(\mathrm{mol} / \mathrm{lit})\end{array}$ & $\begin{array}{c}\mathrm{OCP} \\
(\mathrm{mV})\end{array}$ & $\begin{array}{c}\mathrm{Rs}(\mathrm{Oh} \\
\mathrm{m})\end{array}$ & $\begin{array}{c}\mathrm{R}_{\mathrm{P}}(\mathrm{Oh} \\
\mathrm{m})\end{array}$ & $\mathrm{CPE}(\mathrm{F})$ & $\mathrm{R}^{2}$ \\
\hline 0.1 & 222 & $\begin{array}{c}1.628 \mathrm{e} \\
+2\end{array}$ & $\begin{array}{c}1.656 \mathrm{e} \\
+4\end{array}$ & $\begin{array}{c}8.679 \mathrm{e}- \\
9\end{array}$ & $\begin{array}{c}0.983 \\
1\end{array}$ \\
\hline 0.05 & 240 & $\begin{array}{c}1.240 \mathrm{e} \\
+1\end{array}$ & $\begin{array}{c}1.262 \mathrm{e} \\
+5\end{array}$ & $\begin{array}{c}6.444 \mathrm{e}- \\
11\end{array}$ & $\begin{array}{c}0.996 \\
1\end{array}$ \\
\hline 0.01 & 250 & $\begin{array}{c}5.033 \mathrm{e} \\
+2\end{array}$ & $\begin{array}{c}4.575 \mathrm{e} \\
+4\end{array}$ & $\begin{array}{c}1.944 \mathrm{e}- \\
9\end{array}$ & $\begin{array}{c}0.996 \\
1\end{array}$ \\
\hline 0.005 & 248 & $\begin{array}{c}8.258 \mathrm{e} \\
+2\end{array}$ & $\begin{array}{c}7.440 \mathrm{e} \\
+3\end{array}$ & $\begin{array}{c}3.345 \mathrm{e}- \\
10\end{array}$ & $\begin{array}{c}0.999 \\
5\end{array}$ \\
\hline 0.001 & 257 & $\begin{array}{c}2.611 \mathrm{e} \\
+3\end{array}$ & $\begin{array}{c}4.489 \mathrm{e} \\
+4\end{array}$ & $\begin{array}{c}4.383 \mathrm{e}- \\
10\end{array}$ & $\begin{array}{c}0.999 \\
7\end{array}$ \\
\hline 0.0001 & 257 & $\begin{array}{c}5.938 \mathrm{e} \\
+2\end{array}$ & $\begin{array}{c}2.026 \mathrm{e} \\
+4\end{array}$ & $\begin{array}{c}6.803 \mathrm{e}- \\
7\end{array}$ & $\begin{array}{c}0.998 \\
3\end{array}$ \\
\hline \hline
\end{tabular}

This results show that electrode act as quasi-Nernstian. Low values for CPE indicates that the electrode surface is uniform and has good roughness. High values of $R_{p}$ and $C P E$ reduces current flow from electrode [16,17]. This reduced error of potentiometric measurements and make our electrode as a potentiometric element.

\section{CONCLUSIONS}

Nickel nanoparticles were produced in acidic reducing solutions. Resulted product characterized by scanning electron microscopy (SEM) shows that the product grow in cluster shape and X-ray diffraction (XRD) gives $3.14 \mathrm{~nm}$ for grain size. Novel potentiometric electrode were assembled with the $\mathrm{Ni}$ /graphite/nujol oil ratio same to 20/44/36. The properties of the modified electrodes at different concentrations were studied by electrochemical impedance spectroscopy (EIS) and potentiometry. Our results showed that Nickel nanoparticles increase the electrode/solution interface capacitance, constant phase element (CPE) and also increase the interface resistance. These electrodes that showed good sensitivity, reproducibility and stability can potentiometricaly determine Nickel ions. For this electrode We determined experimental transferred electron number $\left(\mathrm{n}_{\mathrm{exp}}\right)$, electrode temperature coefficient $(\Delta \mathrm{E} / \Delta \mathrm{T})_{\mathrm{p}}$, Gibbs free energy $(\Delta \mathrm{G})$, enthalpy $(\Delta \mathrm{H})$ and entropy $(\Delta \mathrm{S})$. The best response of this electrode acceptable at temperature $308 \mathrm{~K}$.

\section{REFERENCES}

[1]. R. Eluri, B. Paul," Synthesis of nickel nanoparticles by hydrazine reduction: mechanistic study and continuous flow synthesis" J. Nanopart. Res., 14 (2012), 800- 814.

[2]. A.S. Aldwayyan, F.M. Al-Jekhedab, M. Al-Noaimi, B. Hammouti, T. B. Hadda, M. Suleiman, I. Warad, " Synthesis and Characterization of $\mathrm{CdO}$ Nanoparticles Starting from Organometalic Dmphen-CdI2 complex", Int. J. Electrochem. Sci., 8 (2013) 10506- 10514.

[3]. H. Wang, X. Kou, J. Zhang, J. Li, " Large scale synthesis and characterization of $\mathrm{Ni}$ nanoparticles by solution reduction method", Bull. Mater. Sci., 31 (2008) 97-100.

[4]. N. R. Stradiotto, K. E. Toghill, L Xiao, A. Moshar,R. G. Compton, " The Fabrication and Characterization of a Nickel Nanoparticle Modified Boron Doped Diamond Electrode for Electrocatalysis of Primary Alcohol Oxidation", Electroanalysis, 21 (2009) 2627-2633.

[5]. Y. Zhou, E. J. E. Stuart, J. Pillay, S. Vilakazi, R. Tshikhudo, N. V. Rees, R. G. Compton, " Electrodenanoparticle collisions: The measurement of the sticking coefficients of gold and nickel nanoparticles from aqueous solution onto a carbon electrode ", Chemical Physics Letters, 551 (2012) 68-71.

[6]. M. Singh, M. Kumar, F. Štěpánek, P. Ulbrich, P. Svoboda, E. Santava, M.L. Singla, " Liquid-Phase Synthesis of Nickel Nanoparticles stabilized by PVP and study of their structural and magnetic properties", Adv. Mat. Lett., 2 (2011) 409-414.

[7]. A. K. Singh, Q. Xu, " Metal-Organic Framework Supported Bimetallic Ni_Pt Nanoparticles as Highperformance Catalysts for Hydrogen Generation from Hydrazine in Aqueous Solution", ChemCatChem, 5 (2013) 3000- 3004.

[8]. T. Odedairo, J. Chen, Zh. Zhu, " Synthesis of Supported Nickel Nanoparticles via a Nonthermal Plasma Approach and Its Application in CO2 Reforming of Methane", J. Phys. Chem., 117 (2013) 21288-21302.

[9]. K. J. A. Raj, B. Viswanathan, "Synthesis of nickel nanoparticeles with fcc and hep crystal structures", Indian Journal of Chemistry, 50 (2011) 176-179. 
[10]. Yu. G. Morozov, O. V. Belousova, M. V. Kuznetsov, " Preparation of Nickel Nanoparticles for Catalytic Applications ", Inorganic Materials, 47 (2011) 36-40.

[11]. J.A. Langford and A.J.C. Wilson, " Scherrer after sixty years: A survey and some new results in the determination of crystallite size" J. Appl. Crystallogr., 11 (1978) 102-113.

[12]. A. W. Burton, K. Ong, T. Rea, I. Y. Chan, " On the estimation of average crystallite size of zeolites from the Scherrer equation: A critical evaluation of its application to zeolites with one-dimensional pore systems ", Microporous and Mesoporous Materials, 117 (2009) 75-90.

[13]. A. Monshi, M. R. Foroughi, M. R. Monshi, " Modified Scherrer Equation to Estimate More Accurately NanoCrystallite Size Using XRD", World Journal of Nano Science and Engineering, 2 (2012) 154-160.

[14]. P. Zarzycki, K. M. Rosso, Sh. Chatman, T. Preočanin, N. Kallay, W. Piasecki, " Theory, Experiment and Computer Simulation of the Electrostatic Potential at Crystal/Electrolyte Interfaces", Croat. Chem. Acta, 83 (2010) 457-474.

[15]. B.A. Boukamp," A Package for Impedance/Admittance Data Analysis" Solid State Ionics, 136 (1986) 18-19.

[16]. G. A. Ragoisha, N. P. Osipovich, A. S. Bondarenko, J. Zhang, S. Kocha, A. Iiyama, "Characterisation of the electrochemical redox behaviour of $\mathrm{Pt}$ electrodes by potentiodynamic electrochemical impedance spectroscopy ", J Solid State Electrochem, 14 (2010) 531-542.

[17]. G.A. Ragoisha, A.S. Bondarenko," Potentiodynamic electrochemical impedance spectroscopy" Electrochimica Acta, 50 (2005) 1553-1563.

\section{BIOGRAPHIES}

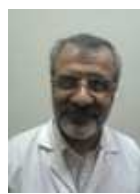

He was born in 1967, received his BS in chemistry from Mazandaran Univ., MSc and $\mathrm{PhD}$ in physical chemistry from Tabriz Univ.. He interested in industrial applications of nano materials.

She was born in 1977, received her BS in educational chemistry from BuAliSina Univ. and MSc in physical chemistry from Damghan Univ.. She presently occupied in chemistry learning.

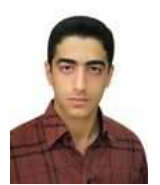

He was born in 1989, received his BS in chemistry from Damghan Univ.. He is MSc student and work on bitumen characteristics. 